\title{
Comparative Studies on Microstructure and Mechanical Properties of Granulated Blast Furnace Slag and Fly Ash Reinforced AA 2024 Composites
}

\author{
Inampudi Narasimha Murthy, Nallabelli Arun Babu, Jinugu Babu Rao* \\ Department of Metallurgical Engineering, Andhra University, Visakhapatnam, India \\ Email: "baburaojinugu@yahoo.com
}

Received 13 March 2014; revised 3 May 2014; accepted 20 May 2014

Copyright (C) 2014 by authors and Scientific Research Publishing Inc.

This work is licensed under the Creative Commons Attribution International License (CC BY). http://creativecommons.org/licenses/by/4.0/

(c) (i) Open Access

\begin{abstract}
Composites are most promising materials of recent interest. Metal matrix composites (MMCs) possess significantly improved properties compared to unreinforced alloys. There has been an increasing interest in composites containing low density and low cost reinforcements. In view of the generation of large quantities of solid waste by products like fly ash and slags, the present expensive manner in which it is discarded, new methods for treating and using these solid wastes are required. Hence, composites with fly ash and granulated blast furnace (GBF) slag as reinforcements are likely to overcome the cost barrier for wide spread applications in automotive and small engine applications. In the present investigation, AA 2024 alloy-5 wt $\%$ fly ash and GBF slag composites separately were made by stir casting route. Phase identification and structural characterization were carried out on fly ash and GBF slag by X-ray diffraction studies. Scanning electron microscopy with energy dispersive $X$-ray spectroscopy EDS was used for microstructure analysis. The hardness and compression tests were carried out on all these alloy and composites. The SEM studies reveal that there was a uniform distribution of fly ash and GBF slag particles in the matrix phase and also very good bonding existed between the matrix and reinforcement. Improved hardness and mechanical properties were observed for both the composites compared to alloy; this increase is higher for Al-fly ash composite than Al-GBF slag composite.
\end{abstract}

\section{Keywords}

Aluminum Alloys, MMCs, Fly Ash, Blast Furnace Slag, Stir Casting

\footnotetext{
*Corresponding author.
}

How to cite this paper: Murthy, I.N., et al. (2014) Comparative Studies on Microstructure and Mechanical Properties of Granulated Blast Furnace Slag and Fly Ash Reinforced AA 2024 Composites. Journal of Minerals and Materials Characterization and Engineering, 2, 319-333. http://dx.doi.org/10.4236/immce.2014.24037 


\section{Introduction}

Metal matrix composites (MMCs) are advanced materials resulting from a combination of two or more materials in which tailored properties are realized. MMCs possess significantly improved properties including high specific strength, damping capacity and good wear resistance compared to unreinforced alloys [1]. Aluminum and its alloys are potentially important materials for automotive and aerospace applications because of its low density and high specific strength. Therefore, the studies on aluminum and its alloys are becoming increasingly important. However, conventional monolithic Aluminum alloys have limitations in achieving good combination of strength, stiffness, toughness and density. To overcome these shortcomings and to meet the ever increasing demand of modern day technology, Aluminum metal matrix composites (AMMCs) are most promising materials of recent interest; these possess much higher specific strength and stiffness, higher wear resistance and lower thermal expansion coefficient in comparison to their base alloy matrices due to the incorporation of suitable particles or fibers into the matrix metal [2] [3].

It is well known that the particle-reinforced metal matrix composites have excellent mechanical properties due to the addition of high strength and high modulus particles like $\mathrm{TiC}, \mathrm{Al}_{2} \mathrm{O}_{3}, \mathrm{SiC}, \mathrm{TiB}_{2}$ etc. In the last few years considerable development has occurred in the potential use of this particle-reinforced metal matrix composites for automotive and aerospace applications. However, cost still remains a major barrier in designing these particles reinforced aluminum composite components for wider applications [4] [5]. A possible way to avoid this handicap of high cost would be the employment of particles obtained from the recycling of some industrial solid wastes. The idea is becoming popular and several studies have been done with various by-products [6] [7].

Among the various low cost reinforcements used, fly ash and slags are the most inexpensive reinforcements with low density available in large quantities as solid waste byproduct from coal combustion in thermal power plants and Iron and steel making industries respectively. More strict environmental regulations have prompted industry to search for new methods of treating their waste byproducts. The thermal power production generates million tons of fly ash as part of the coal combustion byproduct waste stream. This material is composed of non-crystalline oxides of silicon $\left(\mathrm{SiO}_{2}\right)$, aluminum $\left(\mathrm{Al}_{2} \mathrm{O}_{3}\right)$, iron $\left(\mathrm{Fe}_{2} \mathrm{O}_{3}\right)$, calcium $(\mathrm{CaO})$ and minor quantities of other metal oxides (magnesium, sodium, titanium, potassium). The precise composition of fly ash varies depending on the source of the coal being burned. The physical properties of the ash vary with the type and uniformity of the coal, the operating parameters of the power plant and the collection methods employed to separate the ash from the combustion stream [8] [9].

Blast furnace slag is the one major byproduct of pig iron production, regularly generated each year in significant volumes as thousands of tons. Granulated blast furnace slag (GBF slag) is obtained by quenching molten iron slag (a byproduct of iron making) from a blast furnace in water or steam, to produce a glassy, granular product. National Slag Association (NSA)-USA was established in the year 1918 [10]. It is in the process of instituting a University Educational Program as a means to introduce blast furnace slag as a beneficial material to the engineering and environmental departments of major universities in USA. 10 million tons of blast furnace slag is produced in India annually as a byproduct of iron and steel industry. Chemical analyses of blast-furnace slag usually show that four major oxides (lime, magnesia, silica and alumina) make up about $95 \%$ of the total. Minor elements include sulfur, iron, manganese, alkalis, and trace amounts of several others [11]. This byproduct has the potential for increased value if a diversity of suitable end products could be produced from these materials. It has been observed that the GBF slag that is produced in the steel plants in huge quantities is dumped in the dump yard and then later used for road construction mostly in the plant itself; however this usage in practical purpose is only limited in overall consumption of slag.

In view of the generation of large quantities of solid waste byproducts like fly ash and slags, the present expensive manner in which it is discarded, new methods for treating and using these solid wastes are required. Hence, in the present research work an attempt was made to see the possibility of adding these solid wastes as reinforcing particles in Aluminum matrix to produce the low cost, light weight and high specific strength Aluminum metal matrix composites (AMMCs). Composites with either fly ash, GBF slag or both as the reinforcements are likely to overcome the cost barrier for wide spread applications in automotive and small engine applications. It is therefore expected that the incorporation of these solid wastes in aluminum alloy will promote yet another use of this low-cost waste byproduct and, at the same time, has the potential for conserving energy intensive aluminum and thereby, reducing the cost of aluminum products.

In the present investigation AA 2024 alloy was chosen as matrix material because of its wider applications in 
the family of aluminum-copper alloys. This alloy has a higher tensile and yield strength with lower elongation. Typical uses of this alloy are aircraft structures, rivets, hardware, truck wheels and screw machine products. At present very limited information is available on the GBF slag reinforced AA 2024 alloy composites. Therefore the present investigation makes an attempt to synthesize the fly ash and GBF slag reinforced AA 2024 alloy composites by stir casting route; later these composites were characterized in terms of their SEM-EDS, XRD studies, density, hardness and mechanical properties under compression.

\section{Materials and Methods}

\subsection{Synthesis of Fly Ash and Granulated Blast Furnace Slag Reinforced Composites}

In the present investigation, industrial wastes like fly ash and granulated blast furnace (GBF) slag particulates reinforced aluminum based metal matrix composites of $5 \mathrm{wt} \%$ were successfully synthesized by vortex method. The matrix materials used in this study was Al-Cu-Mg alloy (AA 2024) whose chemical composition is shown in Table 1. The reinforcement materials were fly ash and granulated blast furnace slag particulates, which were procured from Thermal power plant and Iron making plant (Blast Furnace area) respectively of Rashtriya Ispat Nigam Limited (RINL), Visakhapatnam Steel Plant, Visakhapatnam, India. The chemical composition of the as received fly ash and granulated blast furnace slag was given in Table 2 and Table 3 respectively. Preheating of the fly ash and granulated blast furnace slag particulates were carried out in a muffle furnace at $300^{\circ} \mathrm{C}$ for 3 hours to get rid of the any moisture presence in them. Figure 1 shows the fly ash powder before and after preheating conditions. As received blast furnace slag was observed coarse in nature; hence it underwent crushing and grinding operation. As received and processed blast furnace slag powders were shown in Figure 2. Dried fly ash and dried \& processed blast furnace slag has been sieved for 15 minutes using BSS meshes ranging in size from 100 to 350 by Rotap Sieve shaker. The results show that the average particle size of the fly ash and blast furnace slag powders is $35 \mu \mathrm{m}$; hence this size was chosen as reinforcement for synthesis of Al based metal matrix composites.

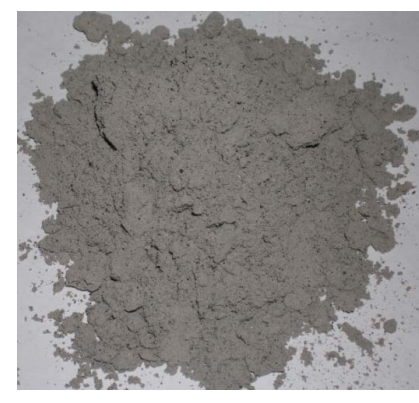

(a)

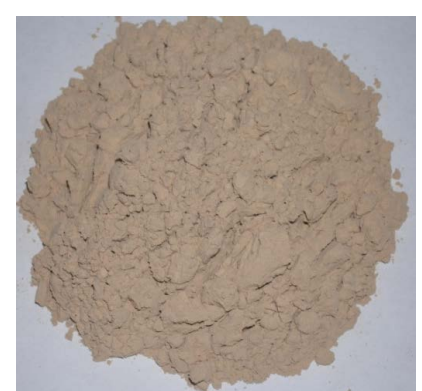

(b)

Figure 1. The fly ash powder used for synthesis of Al-fly ash (ALFA) composites (a) As received condition; (b) After preheating condition.

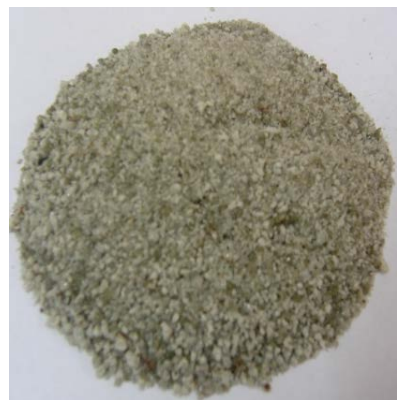

(a)

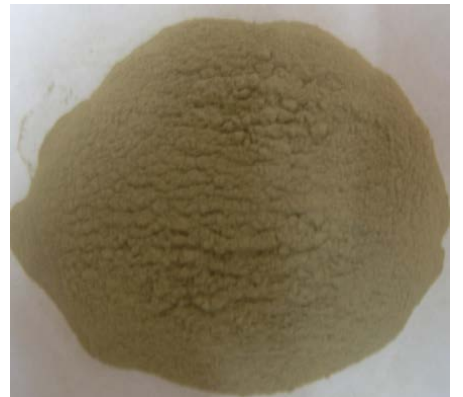

(b)

Figure 2. The granulated blast furnace (GBF) slag powder used for synthesis of Aluminium-granulated blast furnace slag (GBF) slag composites (a) As received condition; (b) After crushing and grinding condition. 
Table 1. Chemical composition of $\mathrm{Al}-4.5 \% \mathrm{Cu}-2 \mathrm{Mg}$ alloy, wt\%.

\begin{tabular}{ccccccccccc}
\hline $\mathrm{Cu}$ & $\mathrm{Mg}$ & $\mathrm{Si}$ & $\mathrm{Fe}$ & $\mathrm{Mn}$ & $\mathrm{Ni}$ & $\mathrm{Pb}$ & $\mathrm{Sn}$ & $\mathrm{Ti}$ & $\mathrm{Zn}$ & $\mathrm{Al}$ \\
\hline 4.52 & 1.938 & 0.066 & 0.663 & 0.131 & 0.075 & 0.029 & 0.021 & 0.013 & 0.118 & Balance \\
\hline
\end{tabular}

Table 2. Chemical composition of as received fly ash, wt\%.

\begin{tabular}{ccccccccc}
$\mathrm{SiO}_{2}$ & $\mathrm{Al}_{2} \mathrm{O}_{3}$ & $\mathrm{Fe}_{2} \mathrm{O}_{3}$ & $\mathrm{TiO}_{2}$ & $\mathrm{CaO}$ & $\mathrm{MgO}$ & $\mathrm{Na}_{2} \mathrm{O}$ & $\mathrm{K}_{2} \mathrm{O}$ & Loss on ignition \\
\hline 58.41 & 30.40 & 8.44 & 2.75 & 1.3 & 1.53 & 1.0 & 1.98 & 2.4 \\
\hline
\end{tabular}

Table 3. Chemical composition of as received granulated blast furnace slag, wt\%.

\begin{tabular}{cccccccc}
\hline $\mathrm{SiO}_{2}$ & $\mathrm{CaO}$ & $\mathrm{FeO}$ & $\mathrm{Al}_{2} \mathrm{O}_{3}$ & $\mathrm{MgO}$ & $\mathrm{MnO}$ & $\mathrm{TiO}_{2}$ & $\mathrm{CaS}$ \\
\hline 34.2 & 34.34 & 0.37 & 18.9 & 9.67 & 0.34 & 0.72 & 1.46 \\
\hline
\end{tabular}

The synthesis of Al-fly ash and Al-GBF slag composites were carried out by stir casting technique. Cylindrical fingers (18 mm diameter and $170 \mathrm{~mm}$ length) of AA 2024 alloy were taken into a graphite crucible and melted in an electric furnace. After maintaining the temperature at $770^{\circ} \mathrm{C}$, a vortex was created using mechanical stirrer made of graphite. While stirring was in progress, the preheated fly ash and blast furnace slag particulates at $500^{\circ} \mathrm{C}$ for $2 \mathrm{hrs}$ were introduced individually to make the fly ash and blast furnace slag reinforced composites respectively. Care was taken to ensure continuous and smooth flow of the particles addition in the vortex. The molten metal was stirred at 400 rpm under argon gas cover; stirring was continued for about 5 minutes after addition of reinforcements to get the uniform distribution in the melt. During stirring small pieces of magnesium ( $0.5 \mathrm{wt} \%)$ were added to the molten metal to enhance the wet ability of reinforcement particles with melt. While the melt was in stirring condition the melt with the reinforced particulates were bottom poured into preheated $\left(200^{\circ} \mathrm{C}\right)$ S.G. iron mould of $18 \mathrm{~mm}$ diameter and $170 \mathrm{~mm}$ height, as shown in Figure 3. Homogenization treatment was carried out at $200^{\circ} \mathrm{C}$ for 24 hrs to relieve the internal stresses and minimize the chemical in homogeneity which may be present in the cast ingots.

\subsection{Metallography and Hardness Studies}

Specimens for metallographic observations were prepared by standard polishing techniques. Scanning electron microscopy (Model: JEOL-JSM 6610LV) with EDAX energy dispersive X-ray spectroscopy (EDS) was used in order to evaluate the morphological changes observed in the fly ash and GBF slag particles and composites. The hardness of the alloy and composites was evaluated using Leco Vickers hardness tester (Model: LV 700-USA). The applied load and dwell times are $2 \mathrm{Kg} \& 15 \mathrm{sec}$ respectively. An average of ten readings was taken for each hardness value.

\subsection{Density and Porosity Calculations}

The density of fly ash and GBF slag particles which were used in fabricating the composites was determined. First, a measuring flask was filled with distilled water to the $100 \mathrm{ml}$ line. It was placed in a bell jar and evacuated to a pressure of between $-86 \mathrm{kPa}$ to $-96 \mathrm{kPa}$ until the water stopped bubbling. This removes any entrapped voids. The flask was then removed and filled to the $100 \mathrm{ml}$ mark with distilled water. The weight of the water filled flask was then recorded as $W T_{2}$.

$15 \mathrm{gm}$ of fly ash $\left(W T_{1}\right)$ was weighed into a flask. The sample was washed down in the flask with distilled water ensuring that the entire sample is under the water. The flask was filled to the $100 \mathrm{ml}$ line. The setup was then placed under a bell jar and evacuated to a pressure of $-86 \mathrm{kPa}$ to $-96 \mathrm{kPa}$ until the sample stopped bubbling. It was removed and filled to the $100 \mathrm{ml}$ mark with distilled water. The weight of the flask with sample and distilled water was then recorded as $\left(W T_{3}\right)$. The density of the fly ash particles was then calculated from equation below.

$$
\text { Density of fly ash }=W T_{1} /\left(W T_{2}-\left(W T_{3}-W T_{1}\right)\right)
$$




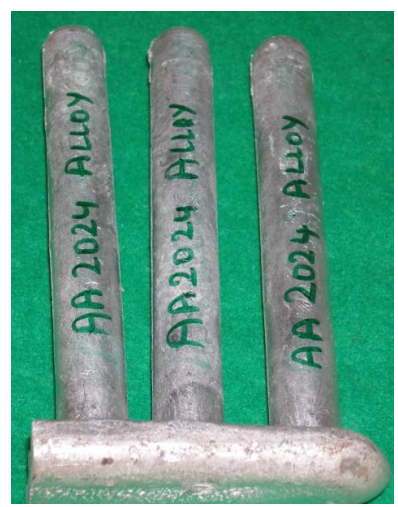

(a)

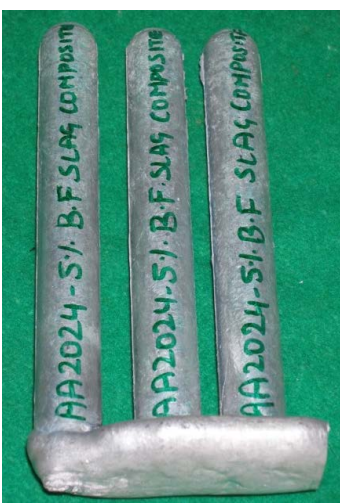

(b)

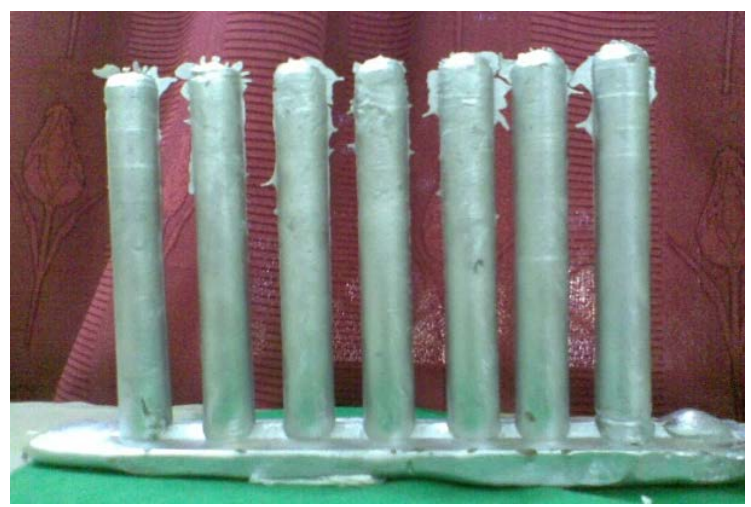

(c)

Figure 3. As cast cylindrical fingers of Al based metal matrix campsites. (a) AA 2024 alloy; (b) Al-5 wt\%. Granulated blast furnace (GBF) slag reinforced composite (c) Al-5 wt\% fly ash reinforced (ALFA) composite.

The same above procedure was adopted for measuring the density of GBF slag. The density of the alloy and composites was measured by the Archimedes drainage method by using the following equation [12]:

$$
\rho_{\text {MMC }}=(m) /\left(\left(m-m_{1}\right) \times \rho_{\mathrm{H}_{2} \mathrm{O}}\right)
$$

where $\rho_{\text {MMC }}$ is the density of the Al-based composite, $m$ is the mass of the composite sample in air, $m_{1}$ is the mass of the same composite sample in distilled water and the density of the distilled water $\left(\rho_{\mathrm{H}_{2} \mathrm{O}}\right)$ at $20^{\circ} \mathrm{C}$ is $0.998 \mathrm{~g} / \mathrm{cm}^{3}$.

Theoretical density calculations, according to the rule of mixture were also used to determine the densities of the composites. This was obtained from the below equation [13].

$$
\rho_{c}=V_{r} \rho_{r}+\left(1-V_{r}\right) \rho_{m}
$$

where $\rho_{c}$ the density of the composite, $V_{r}$ is the weight ratio of reinforcement, $\rho_{r}$ is the density of reinforcement and $\rho_{m}$ is the density of the unreinforced AA 2024 alloy. The porosity of the test materials were also calculated from the following equation [14].

$$
\text { Porosity }(\%)=(1-(\text { measured density } / \text { calculated density })) \times 100
$$

\subsection{Compression Tests}

Compression tests were carried out on cylindrical specimens of AA 2024 alloy and fly ash \& GBF slag reinforced composites of $12 \mathrm{~mm}$ diameter with Height/diameter $\left(H_{0} / D_{0}\right)$ ratio of 1.0. These cylindrical specimens of standard dimensions were prepared using conventional machining operations of turning, facing and drilling. Specimen edges were chamfered to minimize folding. Concentric v-grooves of $0.5 \mathrm{~mm}$ deep were made on the flat surfaces to have a low friction between die and work piece during compression. Standard samples were compressed by placing between the flat platens at a constant cross head speed of $0.5 \mathrm{~mm} / \mathrm{min}$ in dry condition, using a computer controlled servo hydraulic $100 \mathrm{~T}$ universal testing machine (Model: FIE-UTE). Cold work die steel dies (flat flattens) were machined to produce smooth finish to yield low friction. Online plotting of load versus displacement was done continuously through a data acquisition system.

\section{Results \& Discussion}

Fly ashes consist largely of the inorganic residue of coal after the combustion process. They have a complex microstructure, with a mixture of amorphous (usually predominant) and crystalline phases. The primary phase in fly ash is a glassy component, which is mostly derived from dehydroxylation of clay minerals in the parent coal. Dehydroxylation is the chemical process that decomposes one or more hydroxyl $\left(\mathrm{OH}^{-}\right)$groups in the clay minerals thereby reducing them. Other phases present in fly ashes are magnetite, hematite, quartz, mullite and minor quantities of anhydrite. Figure 4 shows the SEM of the fresh fly ash after pre heating condition. From these figures it is evident that the majority of the fly ash particles are spherical in nature and precipitator type fly ash. 


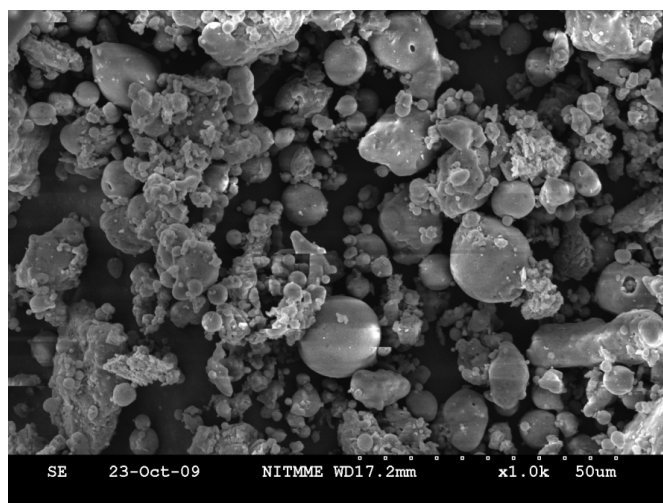

(a)

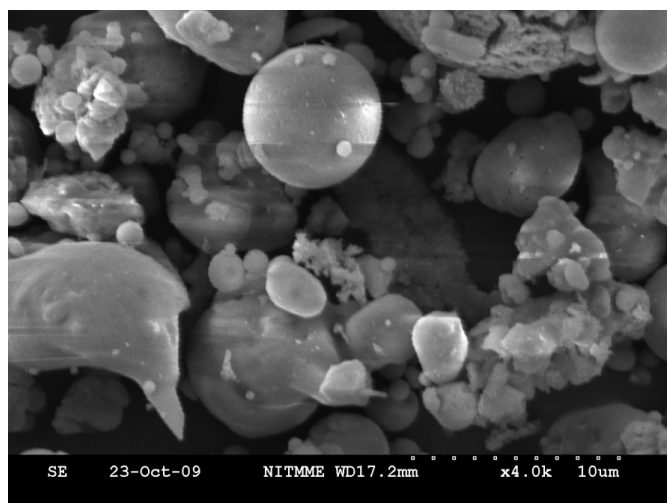

(b)

Figure 4. (a) SEM micrographs of fly ash particles used in fabrication of Al-fly ash (ALFA) composites; (b) Fly ash particles at higher magnification.

The morphology of fly ash particle is controlled by combustion temperature and cooling rate at the thermal power plant. The phase and chemical analysis of the fly ash was shown in Figure 5 and Figure 6. Figure 5 represents the X-ray diffraction (XRD) pattern of fly ash after pre heating condition; which shows the phases present in the fly ash are largely Silica $\left(\mathrm{SiO}_{2}\right)$, Alumina $\left(\mathrm{Al}_{2} \mathrm{O}_{3}\right)$, Mullite $\left(3 \mathrm{Al}_{2} \mathrm{O}_{3} \cdot 2 \mathrm{SiO}_{2}\right)$ and small quantity of Hematite $\left(\mathrm{Fe}_{2} \mathrm{O}_{3}\right)$. EDS spectrum of the fly ash particles as shown in Figure 6. It shows the presence of $\mathrm{Al}, \mathrm{Si}$ and Oxygen peaks correspond to the Silica $\left(\mathrm{SiO}_{2}\right)$, Alumina $\left(\mathrm{Al}_{2} \mathrm{O}_{3}\right)$ and Mullite $\left(3 \mathrm{Al}_{2} \mathrm{O}_{3} \cdot 2 \mathrm{SiO}_{2}\right)$ which are present in the fly ash.

The granulated blast furnace (GBF) slag which was used for this study was made by slag granulation (SG) method. This SG method is similar to the atomization of the liquid to produce fine powder. Due to instant cooling of the slag from liquid phase to solid phase, the grain shape of the atomized slag powders are having mostly in irregular to the angular shape depends on type of media using for atomization. In particular water atomization generates the angular shape particles. The subsequent SEM Figure 7 and Figure 9 support the same. Figure 7 shows the SEM of as received and preheated GBF slag. The slag particles represented an irregular morphology with a mean size of $35 \mu \mathrm{m}$. X-ray diffraction patterns indicated that the majority components in the GBF slag were $\mathrm{CaO}, \mathrm{SiO}_{2}$ with minor amounts of $\mathrm{Al}_{2} \mathrm{O}_{3}$ and $\mathrm{Fe}_{2} \mathrm{O}_{3}$ (Figure 8). The EDS spectrum of the GBF slag was shown in Figure 9. It shows the presence of $\mathrm{Ca}, \mathrm{Si}, \mathrm{Fe}, \mathrm{Al}$ and Oxygen; which are representing to their respective oxides presence in the GBF slag.

The density of the reinforcement particles is an important concern; their incorporation into aluminum alloys leads to either significant increase or reduction in the density of the composite. Low density reinforced aluminum Metal Matrix Composites (MMCs) could be an attractive for rotary parts in automobile and other transportation applications. The density of fly ash and GBF slag particles which were used in fabricating the composites was determined and was found to be 2.09 and $1.5 \mathrm{~g} / \mathrm{cc}$ respectively, as shown in Figure 10. The higher density of fly ash supports the presence of iron oxide.

\subsection{Microstructure of Composites}

Figure 11 shows the SEM micrograph of the AA 2024 alloy. This alloy is a hypoeutectic alloy and consisting of soft aluminum solid solution matrix $(\alpha)$ and hard $\mathrm{CuMgAl}_{2}$ phase. Hence the microstructure is composed of $(\alpha)$ primary grains and a eutectic mixture of $\left(\alpha+\mathrm{CuMgAl}_{2}\right)$. SEM micrographs of AA 2024 alloy-5 wt $\%$ fly ash composite was shown in Figure 12. Figure 12(a) revealed that presence of fly ash particles in AA 2024 alloy matrix and further confirms that there was a uniform distribution of fly ash particles in the base matrix of AA 2024 alloy; Figure 12(b) clearly shows that there were no voids and discontinuities in the composite and also there was a good interfacial bonding between the fly ash particles and matrix materials. The SEM micrograph of AA 2024-5 wt\% GBF slag composite is shown in Figure 13. It also clearly reveals uniform distribution of GBF slag particles in the alloy matrix. The magnified view of the composite microstructure in as-cast $5 \mathrm{wt} \% \mathrm{GBF}$ slag composite in shown in Figure 13(b), which clearly indicates sound interfacial bonding between the matrix and GBF slag particles. 


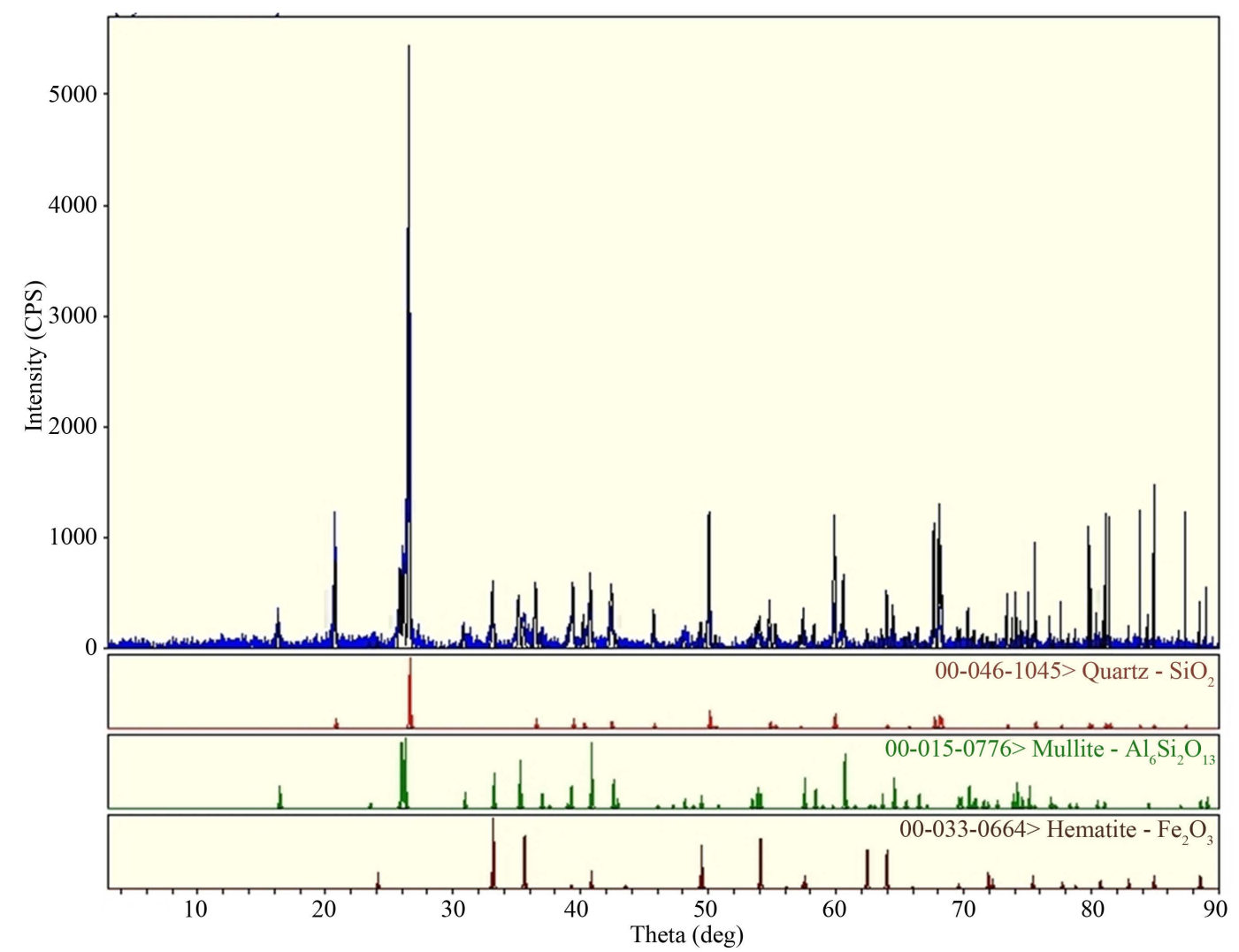

Figure 5. X-ray diffractogram of fly ash particles used in fabrication of Al-fly ash (ALFA) composites.

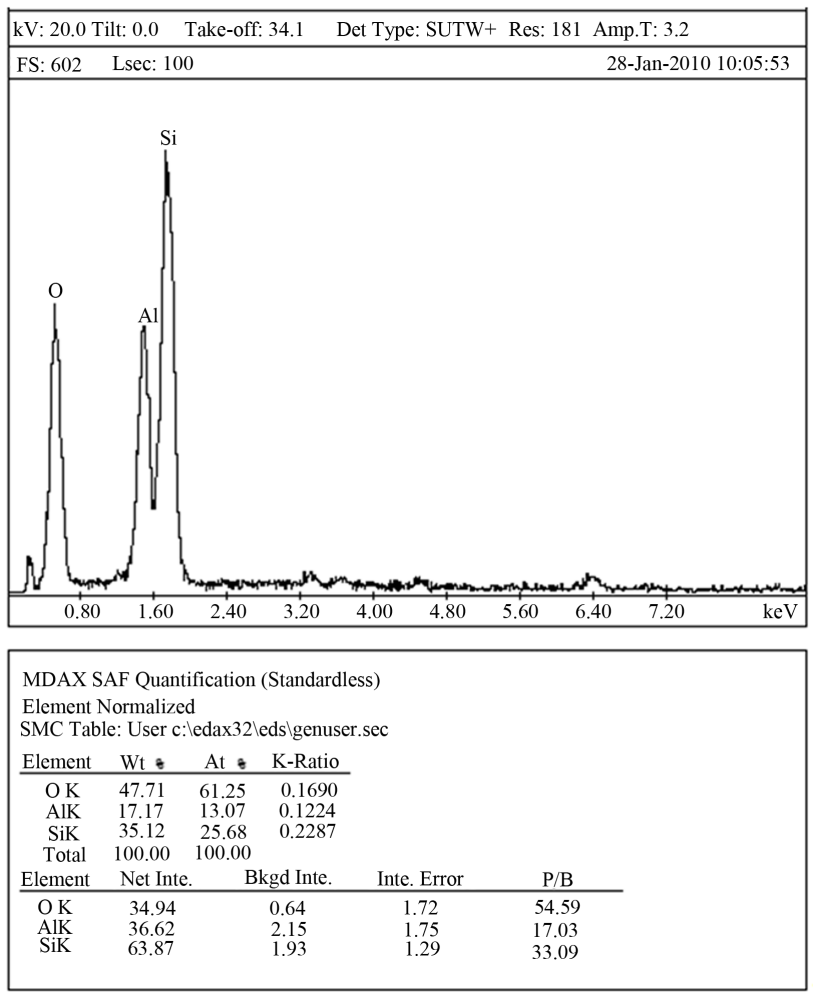

Figure 6. EDS spectrum of fly ash particles. 


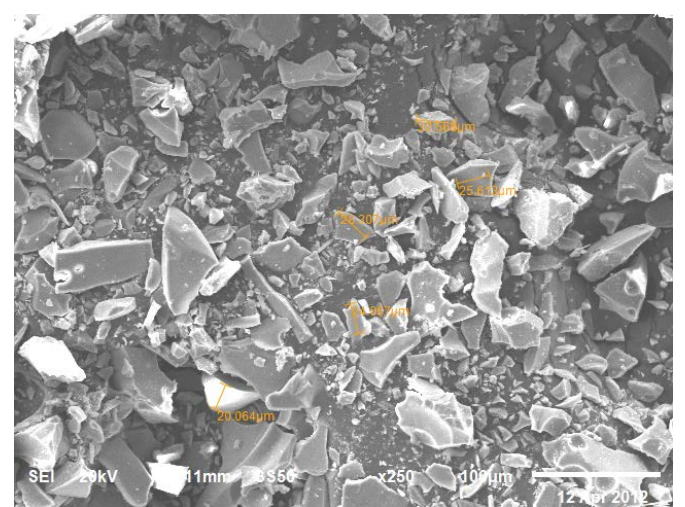

(a)

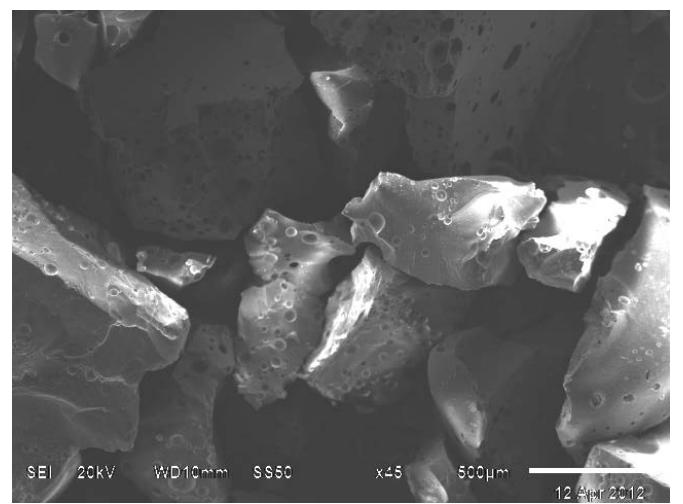

(b)

Figure 7. SEM micrographs of the as GBF slag particles. (a) As received GBF slag with scaling of the particle size; (b) Closer view of the received GBF slag.

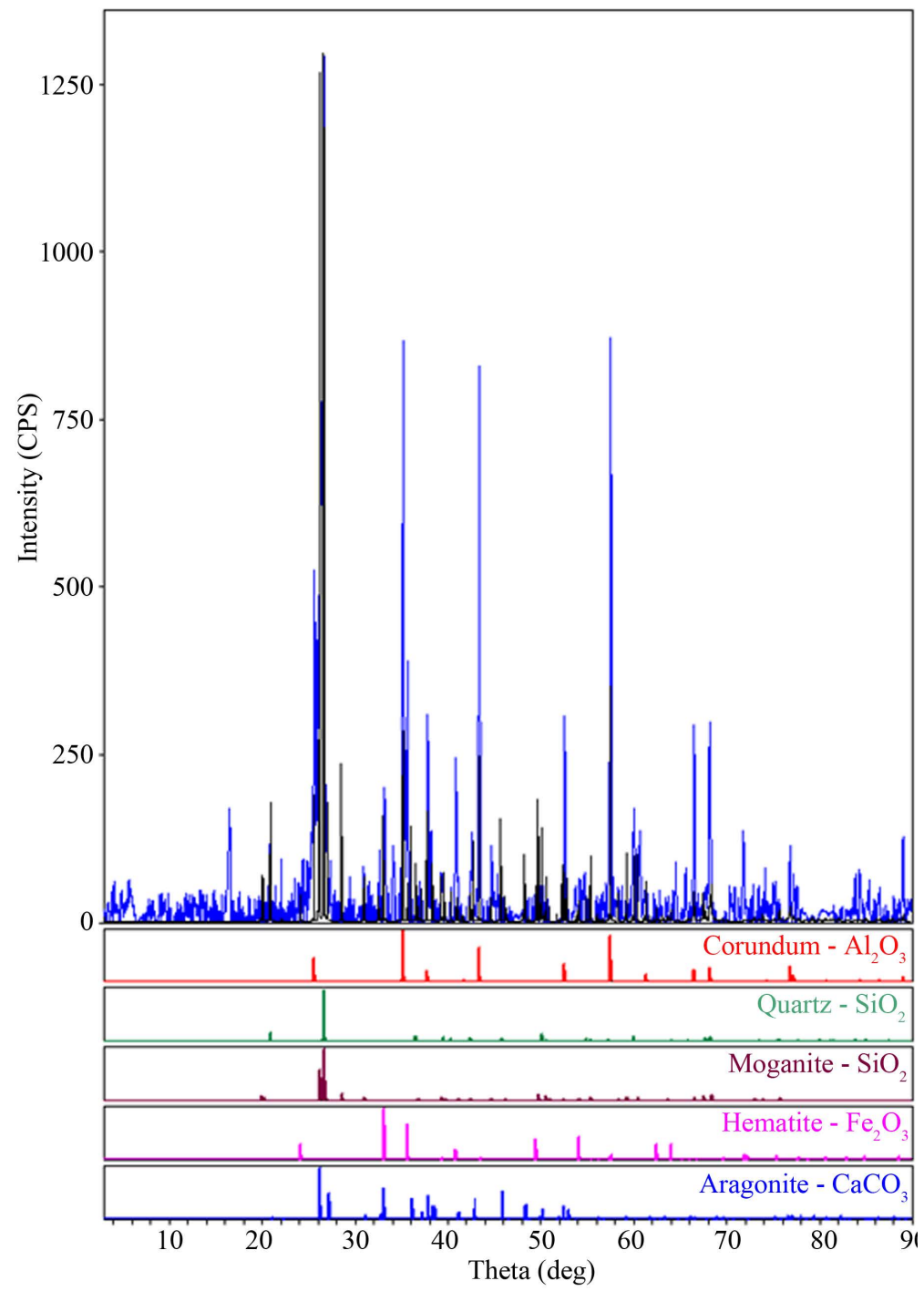

Figure 8. X-ray diffractogram of as received granulated blast furnace (GBF) slag particles used in fabrication of Al-granulated blast furnace (GBF) slag composites. 

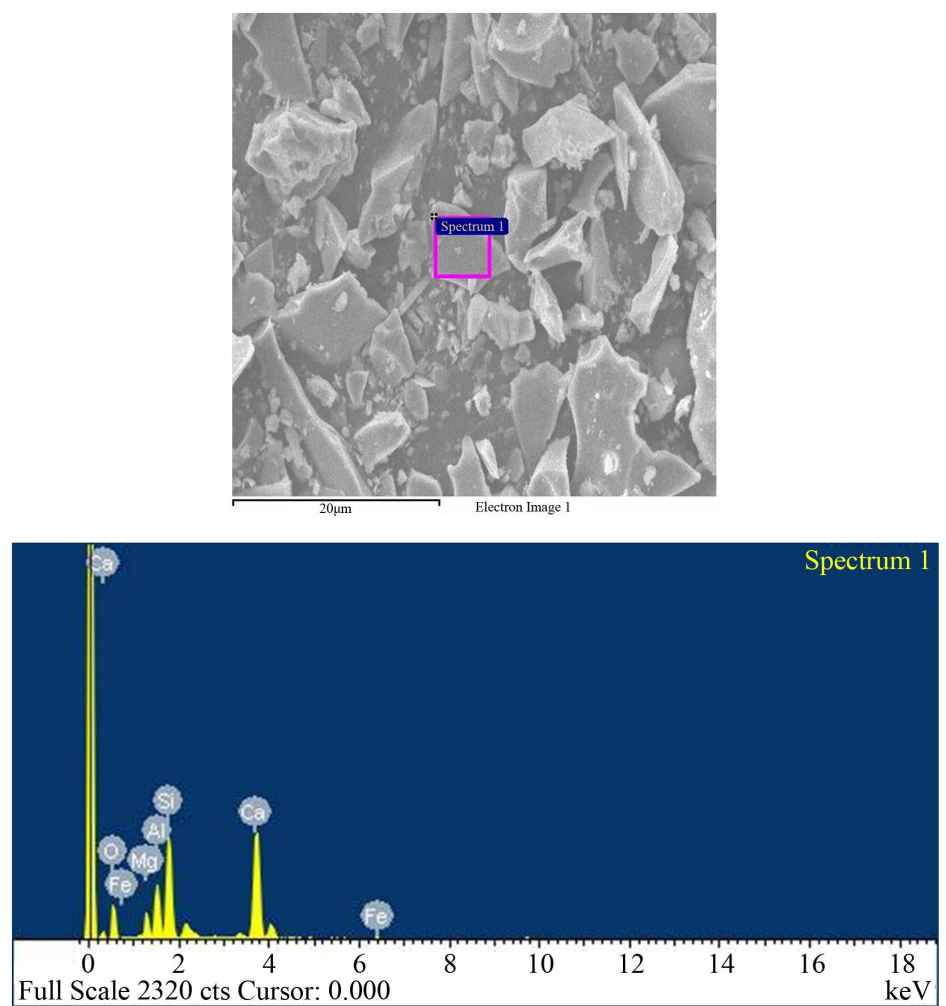

Figure 9. EDS spectrum of granulated blast furnace (GBF) slag particles.

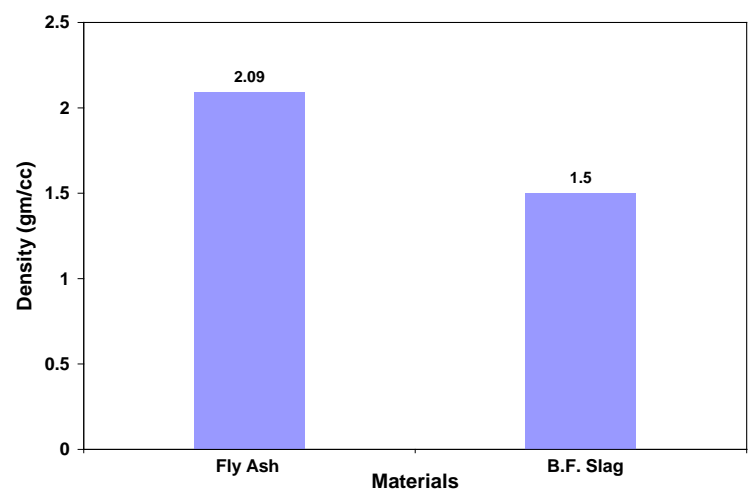

Figure 10. Comparative graph for density measurements of fly ash and GBF slag powders.

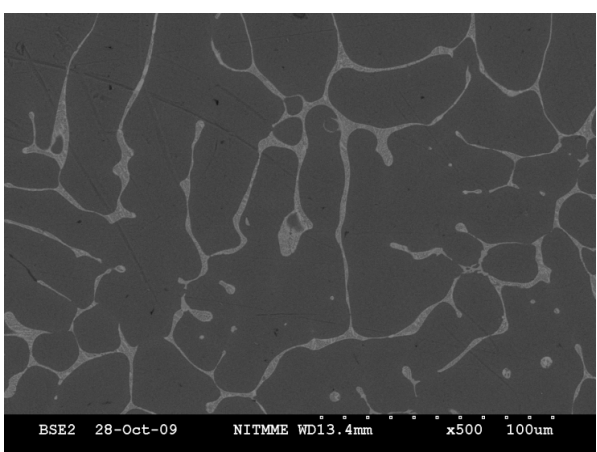

Figure 11. SEM micrograph of as cast AA 2024 alloy. 


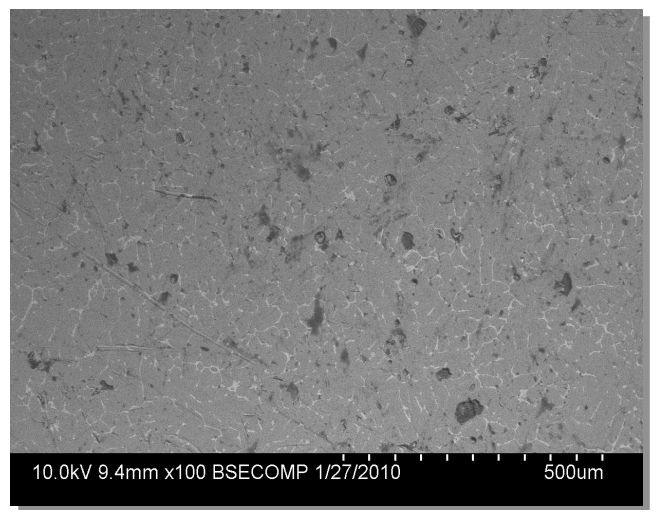

(a)

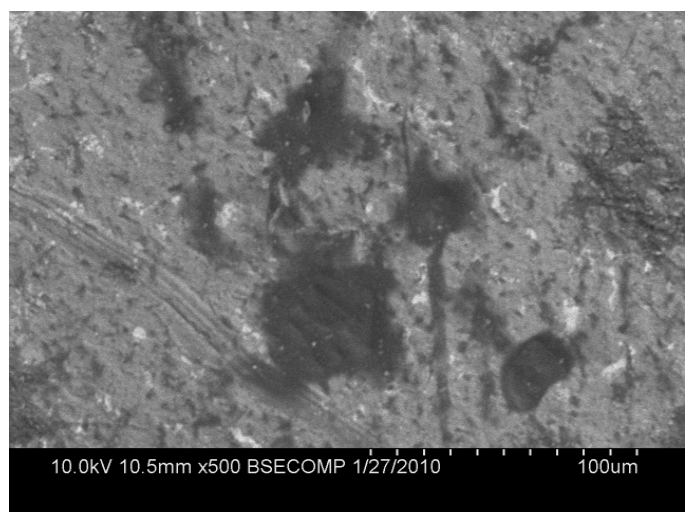

(b)

Figure 12. (a) SEM micrographs of AA 2024 alloy-5 wt\% fly ash composite; (b) Closer view of interface between fly ash particles and the matrix.

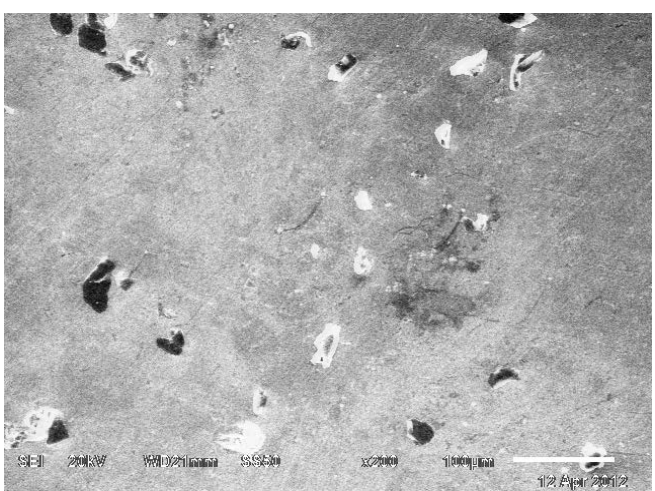

(a)

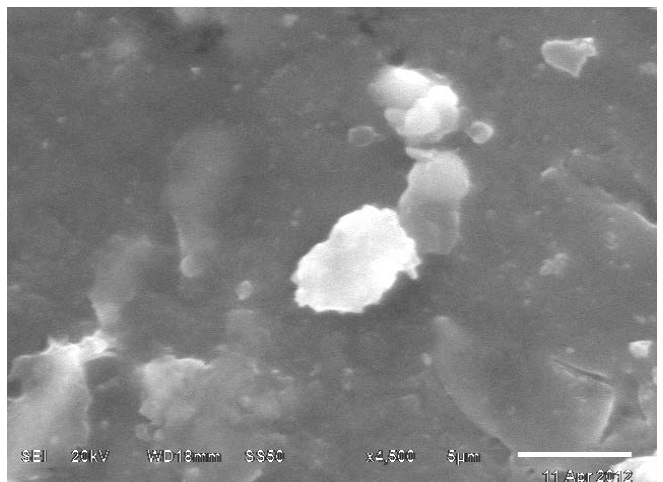

(b)

Figure 13. (a) SEM micrographs of AA 2024 alloy-5 wt\% granulated blast furnace slag composite; (b) Magnified view of the AA 2024 alloy-5 wt\% GBF slag composite.

\subsection{EDX Analysis}

EDS analysis were carried out to confirm the composition of the matrix and the reinforcements in both the AA 2024-5 wt\% fly ash \& AA 2024-5 wt\% GBF slag composites. Figures 14-16 shows the same for AA 2024 matrix, fly ash and GBF Slag respectively. Aluminum, magnesium, copper and small amount of silicon were detected in the EDS analysis of matrix (Figure 14). No oxygen peaks were observed in the matrix area, confirming that the fabricated composite did not contain any additional contamination from the atmosphere. This might be due to a shield of argon gas was maintained during the mechanical stirring while reinforcement addition. Whereas the EDS analysis of fly ash shows the peaks of aluminum, silicon, magnesium and oxygen (Figure 15). These peaks correspond to the alumina $\left(\mathrm{Al}_{2} \mathrm{O}_{3}\right)$, mullite $\left(3 \mathrm{Al}_{2} \mathrm{O}_{3} \cdot 2 \mathrm{SiO}_{2}\right)$ and silica $\left(\mathrm{SiO}_{2}\right)$; which were present in the fly ash even after fabrication of AA 2024-fly ash composite. Figure 16 shows the EDS analysis GBF slag particles, it reveal the presence of calcium, silicon, aluminum, iron, magnesium and oxygen. These peaks correspond to the $\mathrm{CaO}, \mathrm{SiO}_{2}, \mathrm{Al}_{2} \mathrm{O}_{3}, \mathrm{FeO}$ and also confirming the GBF slag presence in the AA 2024-5 wt\% GBF slag composite. During stirring small pieces of magnesium (0.5 wt\%) were added to the molten metal to enhance the wettability of reinforcement particles with melt; this might be reason for the presence of magnesium peaks in both the composites.

\subsection{Mechanical Properties of Composites}

Hardness values of the AA 2024 alloy, AA 2024-5 wt\% Fly ash and AA 2024-5 wt\% GBF Slag composites in as cast condition are depicted in Figure 17. It is evident from this figure that the hardness of the composites is significantly higher than that of the alloy. This increase was observed from 75 VHN for AA 2024 alloy to 124 and 

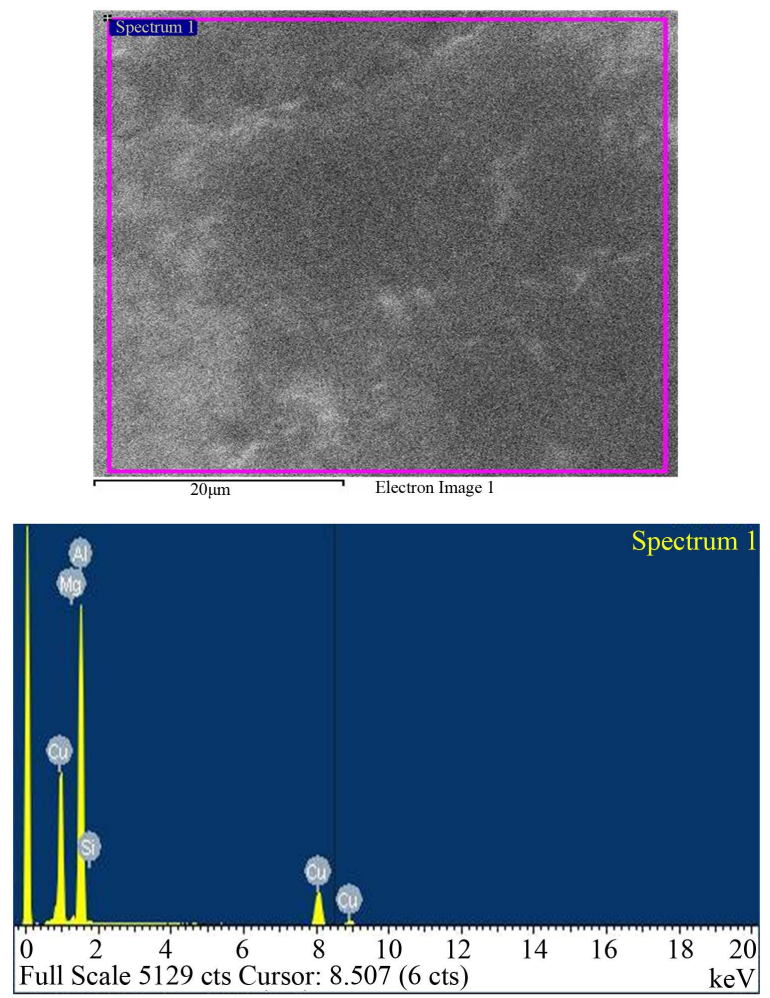

Figure 14. EDS spectrum of base AA 2024 alloy.
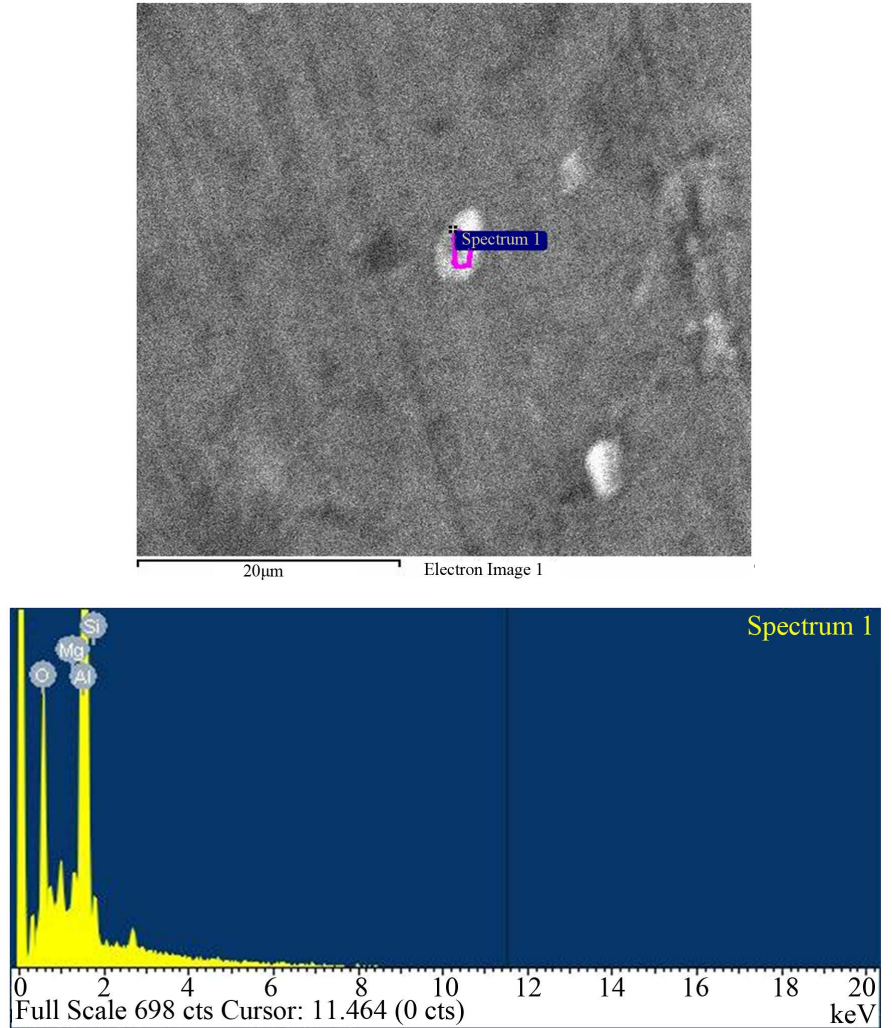

Figure 15. EDS spectrum of fly ash presence in AA 2024-5 wt\% fly ash composite made by Stir cast method. 

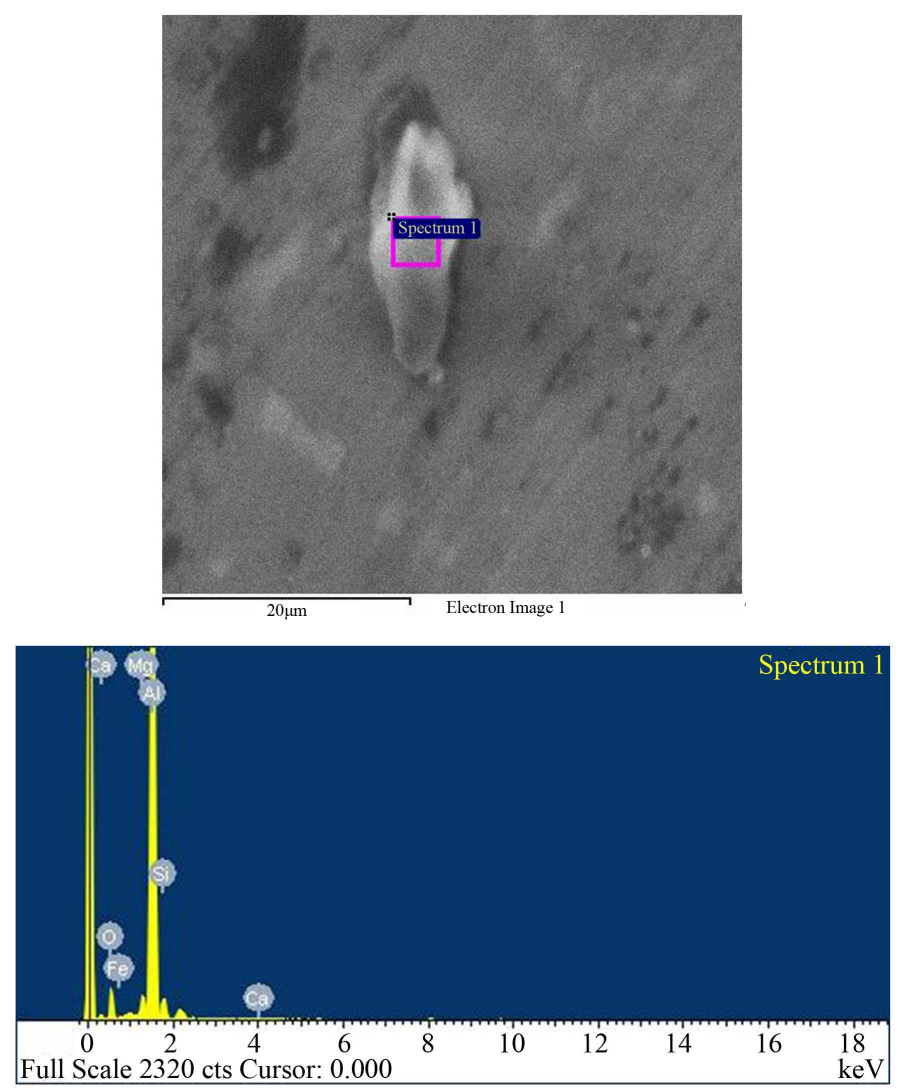

Figure 16. EDS spectrum of blast furnace slag particles presence in AA 2024-5 wt\% GBF slag composite made by stir casting method.

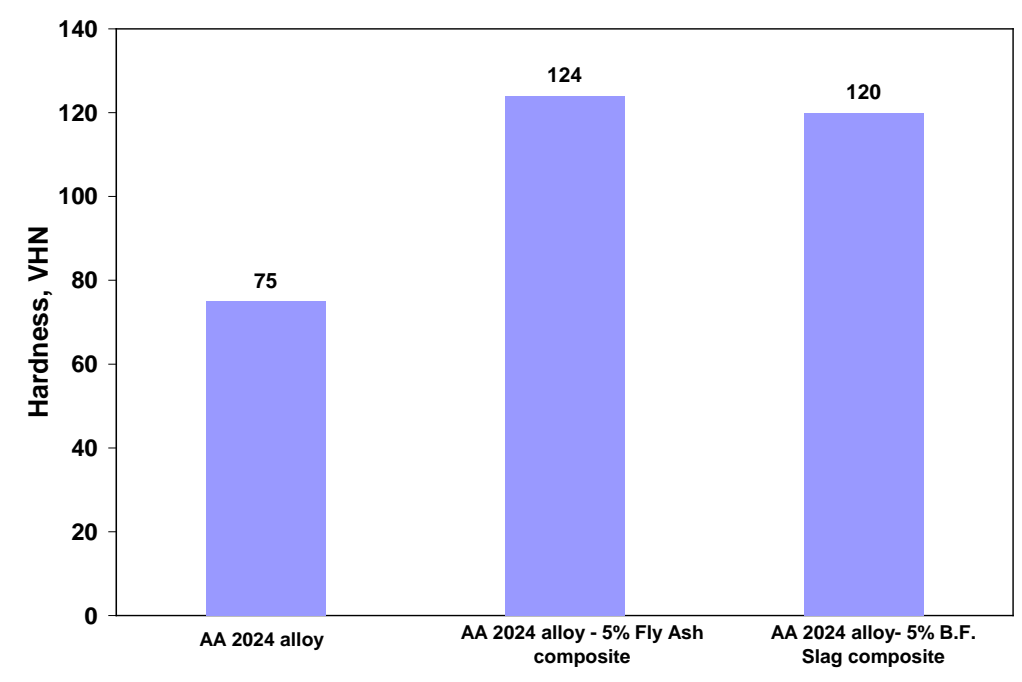

Figure 17. Comparative hardness values for AA 2024 alloy and composites.

120 VHN for AA 2024-5wt\% fly ash and AA 2024-5 wt\% GBF slag composites respectively. Interestingly fly ash reinforced composite shows higher hardness in contrast to GBF slag reinforced composite; this might be due to the presence of fly ash particulates which consists of majority of the alumina and silica which are hard in nature; whereas the GBF slag consists of majority of $\mathrm{CaO}$ with minor quantities of silica and alumina, which makes the GBF slag particles soft in nature.

Table 4 shows the theoretical and measured densities of AA 2024 alloy, AA 2024-5 wt\% Fly ash and 
Table 4. Theoretical and measured densities of AA 2024 alloy and AA 2024-5 wt\% fly ash and AA 2024-5 wt\% Granulated blast furnace (GBF) slag composites along with \% porosity in respective alloy and composites.

\begin{tabular}{|c|c|c|c|c|}
\hline \multirow{2}{*}{ S. No } & \multirow{2}{*}{ Specimen } & \multicolumn{2}{|c|}{ Density $\left(\mathrm{g} / \mathrm{cm}^{3}\right)$} & \multirow{2}{*}{$\%$ Porosity } \\
\hline & & Theoretical & Measured & \\
\hline 1. & AA 2024 alloy & 2.68 & 2.68 & 0 \\
\hline 2. & AA 2024 alloy-5 wt\% fly ash composite & 2.6696 & 2.57 & 3.74 \\
\hline 3. & AA 2024 alloy-5 wt\% GBF slag composite & 2.621 & 2.545 & 2.89 \\
\hline
\end{tabular}

AA 2024-5 wt\% GBF slag composites along with \% porosity in respective alloy and composites. The density of the alloy decreases with the presence of reinforcement; this decrease is varying with respect to the shape, size and type of reinforcement. With $5 \mathrm{wt} \%$ reinforcements of fly ash and GBF slag, the density of composites decreased to $2.57 \& 2.545 \mathrm{~g} / \mathrm{cm}^{3}$ respectively compared to the density of the alloy $2.680 \mathrm{~g} / \mathrm{cm}^{3}$; these values support the lower bulk density of the GBF slag particles $\left(1.5 \mathrm{~g} / \mathrm{cm}^{3}\right)$ compared to relatively higher density of fly ash $\left(2.09 \mathrm{~g} / \mathrm{cm}^{3}\right)$. The measured densities, however, were lower than that obtained from theoretical calculations, as shown in Table 4. The extent of deviation is lower for the presence of GBF slag than fly ash; hence lower porosity values were observed for the GBF slag reinforced composite. This can be attributed to the irregular and angular shape of the GBF slag which enables to better interfacial bonding between reinforcement and matrix. In case of fly ash reinforced composite, fly ash particles used for this studies are majority of round and regular shape, which might be cause for relatively higher porosity values.

Compressive properties of the synthesized alloy and composites can be understood by studying the load-displacement curves. Figure 18 shows the load-displacements curves for AA 2024 alloy and composites during compression testing; and Figure 19 shows the influence of the reinforcement on the compressive strength of AA 2024 alloy and composites with the true stress-true strain curves. The load requirement increased with increase in displacement for both the alloy and composites. The composites show higher loads than the unreinforced alloy; and this increase in compression strength is more for presence of fly ash than GBF slag in the alloy matrix, as shown in Figure 18. The same is confirming from the true stress and true strain results (Figure 19). This indicates that the reinforcement addition leads to improvement in the strength of the composites. The lower strength values for GBF slag reinforced composite can be attributed with the soft nature of GBF slag particles compared to fly ash, same was confirmed by the hardness of both the composites. The strength of the metal matrix composites (MMC) is expected to increase by addition of solid ceramic particles due to the strengthening effects occurred in particulate reinforced composites. These effects include the transfer of stress from the matrix to the particulate, the interaction between individual dislocations and particulates, grain size strengthening mechanism due to a reduction in composite matrix grain size, and generation of a high dislocation density in the matrix of the composite as a result of the difference in thermal expansion between the metal matrix and particulates [15]-[17].

\section{Conclusion}

Industrial wastes like fly ash and GBF slag were utilized successfully for the production of Al based MMCs. Al-fly ash (ALFA) and Al-GBF slag composites were produced by stir casting route successfully. There was a uniform distribution of reinforcement particles in the matrix phase and also existing a good bonding between matrix and reinforcements. The hardness of the composites increased whereas the density of the composites decreased with presence of reinforcement than the base alloy. Higher hardness values were reported for Al-fly ash composite than Al-GBF slag composite. Enhanced mechanical properties were observed for both the composites than alloy under compression.

\section{Acknowledgements}

The authors thank the Department of Science and Technology-Fly Ash Unit-New Delhi, India for their financial support under DST-FAU project (File no: No.FAU/DST/600 (52)/(R)/2012-13); and Department of Metallurgical Engineering, Andhra University College of Engineering, Visakhapatnam, India for providing necessary support in conducting the experiments; and also Dr. K Siva Prasad, MME, NIT-Trichy, India for his support in 


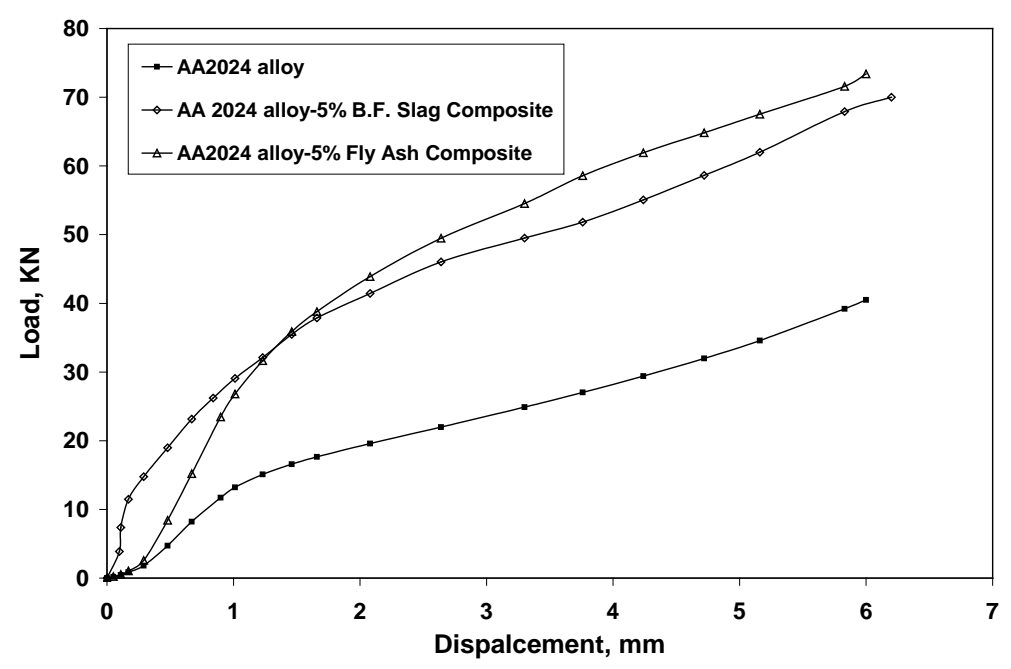

Figure 18. Load-displacement curves for AA 2024 alloy and composites.

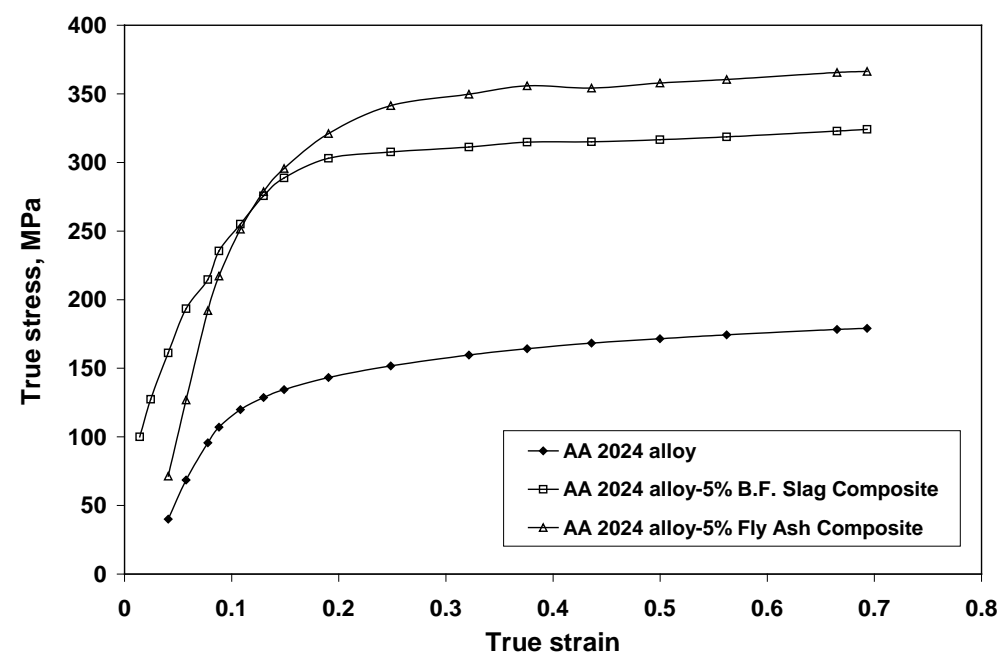

Figure 19. True stress vs true strain curves for AA 2024 alloy and composites.

SEM-EDX studies. Special thanks to RINL, Visakhapatnam Steel Plant, Visakhapatnam for supply of fly ash \& GBF slag for this study.

\section{References}

[1] Akio, K., Atsushi, O., Toshiro, K. and Hiroyuki, T. (1999) Fabrication Process of Metal Matrix Composite with Nano Size SiC Particle Produced by Vortex Method. Journal of Japan Institute of Light Metals, 49, 149-154. http://dx.doi.org/10.2464/jilm.49.149

[2] Rohatgi, P.K. (2001) Cast Metal Matrix Composites Past, Present and Future. In: Invited Silver Anniversary Lecture by American Foundry Society, AFS Transactions, 633.

[3] Rohatgi, P.K., Gupta, N. and Daoud, A. (2008) Synthesis and Processing of Cast Metal Matrix Composites and Their Applications. ASM Handbook. Casting: Vol. 15. ASM International, 1149-1164.

[4] Hosking, F.M., Folgar Portillo, F., Wunderlin, R. and Mehrabian, R. (1982) Composites of Aluminium Alloys: Fabrication and Wear Behaviour. Journal of Materials Science, 17, 477-498. http://dx.doi.org/10.1007/BF00591483

[5] Weiss, D. (1996) Using Metal Matrix Composite Castings. Processing, Properties and Applications of Cast Metal Matrix Composites, Cincinnati, 289.

[6] Rohatgi, P.K., Guo, R.Q., Huang, P. and Ray, S. (1997) Friction and Abrasion Resistance of Cast Aluminum Alloy-Fly Ash Composites. Metallurgical and Materials Transactions A, 28, 245-250. 
[7] Flores-Vélez, L.M., Chávez, J., Hernández, L. and Domınguez, O. (2001) Characterization and Properties of Aluminium Composite Materials Prepared by Powder Metallurgy Techniques Using Ceramic Solid Wastes. Materials and Manufacturing Processes, 16, 1-16. http://dx.doi.org/10.1081/AMP-100103693

[8] Kumar, V., Abraham Zacharia, K. and Sharma, P. (2007) Fly Ash Utilization: Indian Scenario \& Case Studies. http://www.tifac.org.in/news/flyindia.htm

[9] Matsunaga, T., Kim, J.K., Hardcastle, S. and Rohatgi, P.K. (2002) Crystllinity and Selected Properties of Fly Ash Particles. Materials Science and Engineering A, 325, 333-343. http://dx.doi.org/10.1016/S0921-5093(01)01466-6

[10] http://www.nationalslag.org/

[11] Reginald Bashforth, G. (1973) The Manufacture of Iron and Steel, Vol. 1. B.I. Publications, New Delhi, 122-136.

[12] Wu, G.H., Dou, Z.Y., Jiang, L.T. and Cao, J.H. (2006) Damping Properties of Aluminium Matrix-Fly Ash Composites. Materials Letters, 60, 2945-2948. http://dx.doi.org/10.1016/j.matlet.2006.02.018

[13] Ashby, M.F. and Jones, D.R.H. (1980) Engineering Materials: An Introduction to Their Properties and Applications. Pergamon Press, New York.

[14] (2004) Indiana University. http://www.geology.iupui.edu/research/SoilsLab/procedures/bulk/Index.htm

[15] Natarajan, N., Vijayarangan, S. and Rajendran, I. (2006) Wear Behaviour of A356/25SiCp Aluminium Matrix Composites Sliding against Automobile Friction Materials. Wear, 261, 812-822. http://dx.doi.org/10.1016/j.wear.2006.01.011

[16] Akhlaghi, F. and Zare-Bidaki, A. (2009) Influence of Graphite Content on the Dry Sliding and Oil Impregnated Sliding Wear Behavior of Al 2024-Graphite Composites Produced by in Situ Powder Metallurgy Method. Wear, 266, 37-45. http://dx.doi.org/10.1016/j.wear.2008.05.013

[17] Valdez, S., Campillo, B., Perez, R., Martinez, L. and Garcia, A. (2008) Synthesis and Micro Structural Characterization of Al-Mg Alloy-SiC Particle Composite. Materials Letters, 62, 2623-2625.

http://dx.doi.org/10.1016/j.matlet.2008.01.002 
Scientific Research Publishing (SCIRP) is one of the largest Open Access journal publishers. It is currently publishing more than 200 open access, online, peer-reviewed journals covering a wide range of academic disciplines. SCIRP serves the worldwide academic communities and contributes to the progress and application of science with its publication.

Other selected journals from SCIRP are listed as below. Submit your manuscript to us via either submit@scirp.org or Online Submission Portal.
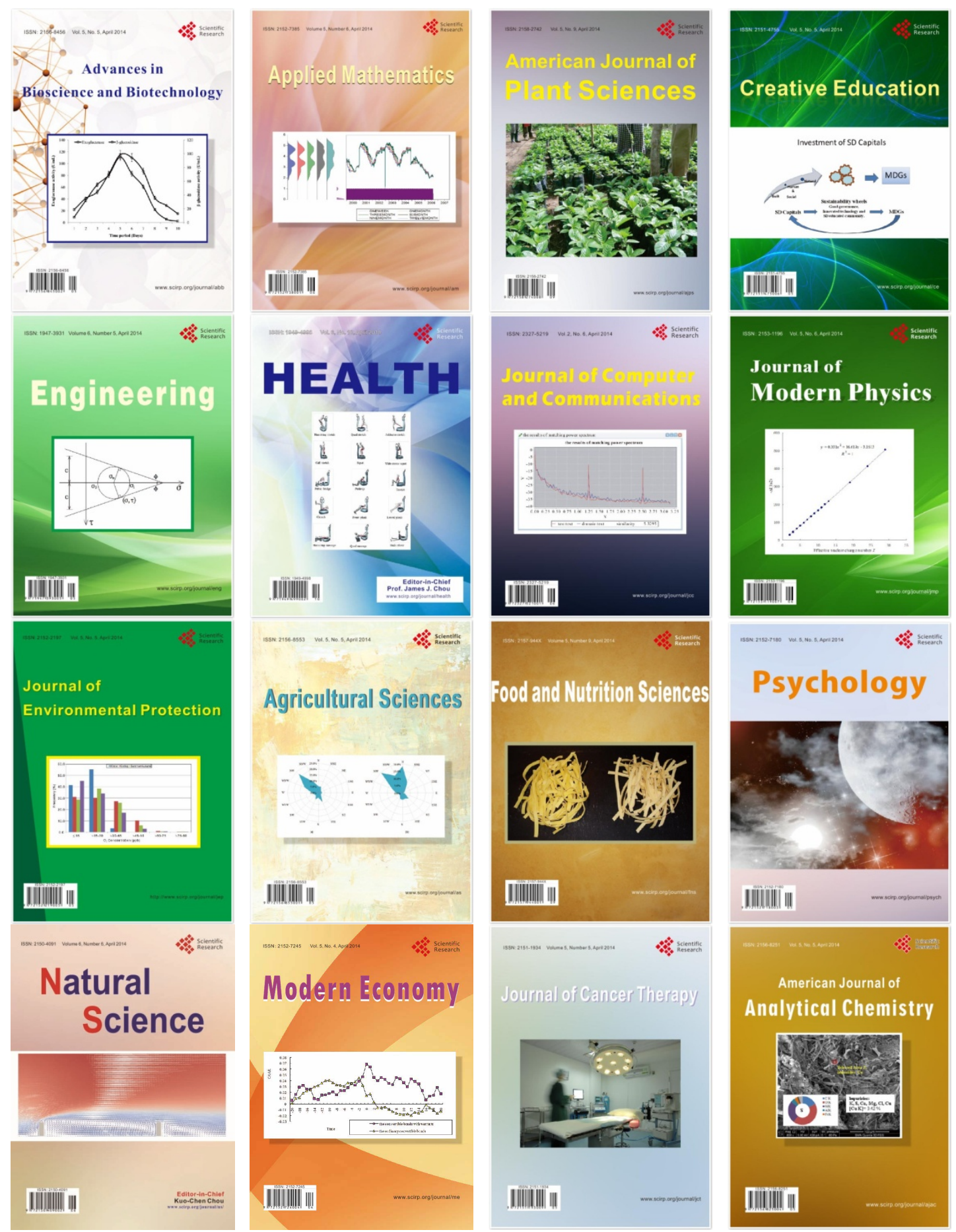